\title{
Analysis of the Impact of LeTV's Big Shareholders' Stock Pledge on Business Performance
}

\author{
Li Yongqing 1' a, Guo Haolei' b \\ ${ }^{1} X i$ 'an University of Science and Technology, Xi'an,Shan'xi,China \\ 2Xi'an University of Science and Technology, Xi'an,Shan'xi,China \\ a564967435@qq.com,b670258453@qq.com \\ ${ }^{*}$ Corresponding author Guo Haolei
}

Keywords: LeTV; major shareholder; equity pledge; operating performance

\begin{abstract}
Private listed companies have higher credit requirements than state-owned enterprises, and financing is more difficult. In order to alleviate these financing difficulties, equity pledges have emerged. Equity pledge has won the favor of many corporate shareholders because it is simple and flexible, and it helps maintain control. However, the behavior of equity pledges tends to cause the separation of control rights and cash flow rights, triggering agent conflicts and negatively affecting business performance. It also easily leads to corporate earnings management and manipulation of profits. Then, how does the shareholder's equity pledge affect the company's operating performance? Recently, LeTV's financial crisis has been hot. This article through LeTV's specific case, to build a business performance evaluation model, to explore LeTV's frequent equity pledge behavior on its business performance, and to get some inspiration.
\end{abstract}

\section{乐视网大股东股权质押对经营业绩影响分析 \\ 李永清 $1, a$, 郭浩蕾 ${ }^{2}, b$ \\ 1西安科技大学管理学院, 西安, 陕西, 中国 \\ 2西安科技大学管理学院, 西安, 陕西, 中国 \\ a564967435@qq.com, b670258453@qq.com \\ *通讯作者 郭浩蕾}

关键词：乐视网；大股东；股权质押；经营业绩

中文摘要：民营上市企业相对于国企来说信贷要求高, 融资比较困难。为了解决这一问题, 股权质押应运而生，并以其简单灵活，有利于维持控制权等优势的得到了众多企业大股东的 青睐。但股权质押行为容易造成控制权和现金流权分离, 引发代理矛盾，对经营业绩产生负 面的影响。而且也容易导致企业盈余管理, 操纵利润。那么, 大股东的股权质押对公司的经 营业绩究竟影响如何呢? 近来, 乐视网的财务危机热点不断, 本文通过乐视网这一具体案例, 构建经营业绩评价模型，探讨乐视网频繁的股权质押行为对其经营业绩的影响，并由此得到 一些启示。

1. 引言

我国市场经济的不断发展与完善使得银行等金融机构对民营企业的信贷要求越来越严格, 投资者对于资金投向也变得更加严谨, 这在一定程度上提高了借贷与投资的安全性, 但也让 许多民营企业开始不得不面对融资难的问题。股权质押以股份作为出质品, 流动性强且方便 
快捷，丰富了民营企业的融资方式。目前，股权质押的规模已经非常壮大，在A股市场中已 经开始利用股权质押融资的个股已经由三千余只, 出质股权的总市值已达五万亿元。虽然股 权质押为企业带来了大量的融资机会，但高质押率背后的风险如何，股权质押对于公司的经 营业绩又有怎样的影响还有待我们探究。本文以乐视网频繁的股权质押行为为例, 剖析其大 股东股权质押与公司经营业绩之间的关系，希望从中得到一些启示。

\section{2. 股权质押优势与风险}

股权质押是指股东用自身持有的上市公司股权作为质押物，从而向银行等金融机构取得 贷款的融资行为, 其优势如下。第一, 股权质押是以上市公司股权作为出质品, 上市公司的 股票信息较为公开, 而且具有良好的流动性, 而且可以随时根据股票的市场价值进行价值评 估，较为公正且易操作。第二，与债券等融资当时相比较成本低。第三点，股权质押不会降 低大股东的持股比例，公司的控制权仍在股东手里。

相对的，股权质押融资也存在许多风险。当被质押的股权股价下跌，接近预定的平仓线 时, 出质方可能会被要求追加担保, 如果无法及时做出担保就会面临被强制平仓的危险, 从 而丧失公司的控制权。另外, 大股东在将股权进行质押后, 很可能为了稳定股价而进行正向 盈余管理, 调节利润。再者, 股权质押行为会使企业的现金流权和控制权分离程度加大, 代 理冲突加大，从而会对公司业绩带来一些消极影响。

\section{3. 背景介绍}

\section{1 乐视网简介}

乐视网（300104）是行业内第一家IPO上市的企业，乐视的市值曾高达过1600多亿。其在 2012年提出了 “平台 + 内容+终端+应用” 多元化战略布局，同时涉足手机、电视、体育、金 融、汽车、房地产等众多产业, 从最初的网络视频业务, 发展成如今的七大子业务。在这样 快速多元化扩张的背后需要的是雄厚资金实力的支持, 2017年乐视的资金链危机全面爆发, 公司经历了高管变更、巨额亏损、长时间停牌等一系列事件，甚至面临退市风险。

\section{2 资金不足原因}

乐视出现资金大量缺口的最主要原因就是多元化的快速扩张。适当相关的多元化战略可 能会给企业带来较好的协同效应, 但在主业并不殷实的情况下盲目扩张, 只会分散公司的现 金流, 无法达到资源的有效整合。在乐视的生态系统中, 无论市手机、电视, 还是汽车、互 联网金融等, 这些子业务所涉及的行业, 竞争都非常激烈, 乐视在这些行业中并没有很大的 竞争力。为了迅速占领市场, 乐视的手机、电视这些终端产品采取的都是低价销售的模式, 企业自身造血功能很弱，有限的现金流根本无法抵挡长期的亏损，资金链随时可能断裂。

\section{3 股权质押概况}

\section{表1 累计质押情况}

\begin{tabular}{|c|c|c|c|c|c|c|c|}
\hline 年度 & 2011 & 2012 & 2013 & 2014 & 2015 & 2016 & 2017 \\
\hline 累计质押股数（万股） & 4,400 & 6,104 & 18,528 & 27,279 & 60,855 & 61,432 & 101,954 \\
\hline 累计占出质方持有比例 & $42.73 \%$ & $59.27 \%$ & $49.83 \%$ & $73.36 \%$ & $77.74 \%$ & $89.97 \%$ & $99.54 \%$ \\
\hline 累计占公司总股本比例 & $20 \%$ & $27.74 \%$ & $23.20 \%$ & $32.43 \%$ & $32.79 \%$ & $31.00 \%$ & $25.52 \%$ \\
\hline
\end{tabular}

从表1可以看出贾跃亭所持股份的累计质押率是逐年增长的。乐视网上市以来进行了大量 融资, 直接间接融资总额已达三百多亿, 融资数额可以说非常巨大, 但乐视仍然很缺钱。贾 跃亭和贾跃芳在公司上市的第二年就进行了三次股权质押行为, 累计质押股数5500万股, 占 到了公司总股本的25\%。2013和2014两年期间贾跃亭姐弟二人质押非常频繁，累计股权质押 
达到了28次。贾跃亭在 2015 年 10 月一次性将其所持股份的 $64.81 \%$ 进行质押，这次质押股份占 公司总股本的比例为 $27.34 \%$, 是乐视规模最大的一次质押行为。截止到 2018 年3月, 贾跃亭累 计质押股数为 $1,019,540,000$ 股，质押数量占其持有股份的 $99.54 \%$, 质押比例达到历史最高。 目前，乐视前CEO所有用于质押式回购的股票都已经跌破预定的平仓线，悉数爆仓。

\section{4. 股权质押对经营业绩的影响}

\section{1 模型构建}

表2 经营业绩评价指标

\begin{tabular}{c|c|c|c|c}
\hline 指标类型 & 偿债能力 & 盈利能力 & 营运能力 & 发展能力 \\
\hline \multirow{3}{*}{ 指标名称 } & 流动比率 $(\mathrm{X} 1)$ & 资产报酬率 $(\mathrm{X} 4)$ & 应收账款周转率 $(\mathrm{X} 7)$ & 总资产增长率 $(\mathrm{X} 10)$ \\
\cline { 2 - 5 } & 动比率 $(\mathrm{X} 2)$ & 营业毛利率 $(\mathrm{X} 5)$ & 流动资产周转率 $(\mathrm{X} 8)$ & 营业收入增长率 $(\mathrm{X} 11)$ \\
\cline { 2 - 4 } & 资产负债率 $(\mathrm{X} 3)$ & 营业净利率 $(\mathrm{X} 6)$ & 总资产周转率 $(\mathrm{X} 9)$ & 净利润增长率 $(\mathrm{X} 12)$ \\
\hline
\end{tabular}

本文选取的经营业绩评价指标均为比例指标，增大样本量，本文将乐视网自上市以来每 年的季报、半年报、年报的财务数据作为研究样本, 运用因子分析的统计方法提取公因子, 对乐视网进行经营业绩评价。

\section{2 实证分析}

\subsection{1 因子分析过程}

首先通过 $\mathrm{KMO}$ 检验和Bartlett球形检验测定样本是否适合做因子分析, 结果显示, KMO 值为 0.578 , 大于 0.5 。Bartlett球度检验统计量为 422.632 , 结果较显著, 且 $S i g=0.000$, 表示可 以拒绝 0 假设, 综上说明, 所选数据较为适宜进行因子分析。

\section{表3 解释的总方差}

\begin{tabular}{|c|c|c|c|c|c|c|c|c|c|}
\hline \multirow[b]{2}{*}{ 组件 } & \multicolumn{3}{|c|}{ 初始特征值 } & \multicolumn{3}{|c|}{ 提取载荷平方和 } & \multicolumn{3}{|c|}{ 旋转载荷平方和 } \\
\hline & 总计 & 方差百分比 & 累积 \% & 总计 & 方差百分比 & 累积 \% & 总计 & 方差百分比 & 累积 \% \\
\hline 1 & 4.523 & 37.693 & 37.693 & 4.523 & 37.693 & 37.693 & 3.578 & 29.813 & 29.813 \\
\hline 2 & 3.038 & 25.318 & 63.011 & 3.038 & 25.318 & 63.011 & 2.997 & 24.973 & 54.786 \\
\hline 3 & 2.012 & 16.763 & 79.775 & 2.012 & 16.763 & 79.775 & 2.216 & 18.467 & 73.253 \\
\hline 4 & 1.378 & 11.486 & 91.260 & 1.378 & 11.486 & 91.260 & 2.161 & 18.008 & 91.260 \\
\hline
\end{tabular}

表3截取了特征值大于 1 的前四个因子的总方差情况，累积占 $91.260 \%$ ，所以提取前四个因 子作为主因子。根据表4给出的公因子在各指标上的载荷, 可以将公因子 1 命名为长期偿债能 力和盈利能力因子, 公因子 2 命名为营运能力因子, 公因子 3 命名为短期偿债能力因子, 公因 子4命名为发展能力因子。

表4 旋转后的成分矩阵

\begin{tabular}{|c|c|c|c|c|c|c|c|c|c|c|c|c|}
\hline & $\mathrm{X} 1$ & $\mathrm{X} 2$ & $\mathrm{X} 3$ & $\mathrm{X} 4$ & $\mathrm{X} 5$ & $\mathrm{X} 6$ & $\mathrm{X} 7$ & $\mathrm{X} 8$ & $\mathrm{X} 9$ & $\mathrm{X} 10$ & $\mathrm{X} 11$ & $\mathrm{X} 12$ \\
\hline 1 & -0.141 & 0.029 & -0.65 & 0.859 & 0.98 & 0.933 & 0.33 & -0.06 & -0.15 & 0.038 & 0.255 & 0.604 \\
\hline 2 & -0.008 & -0.051 & 0.245 & 0.398 & -0.1 & -0.01 & 0.91 & 0.958 & 0.952 & 0.175 & 0.227 & 0.156 \\
\hline 3 & 0.979 & 0.984 & 0.047 & -0.15 & -0.02 & -0.07 & 0.03 & -0.173 & 0.017 & -0.04 & -0.475 & -0.031 \\
\hline 4 & -0.005 & -0.112 & 0.55 & 0.053 & 0.06 & 0.298 & 0.11 & 0.157 & 0.228 & 0.898 & 0.607 & 0.697 \\
\hline
\end{tabular}

\subsection{2 因子得分}

通过计算我们得到了经营业绩的得分情况。在此我们只截取每年度因子得分情况, 因为 2017年年报还未公布, 我们选取2017年第三季度得分作为该年份的年度因子得分, 具体如下 表所示。 
表5＼cjkstart年度因子得分情况

\begin{tabular}{|c|c|c|c|c|c|c|c|}
\hline 截止日期 & $2011 / 12 / 31$ & $2012 / 12 / 31$ & $2013 / 12 / 31$ & $2014 / 12 / 31$ & $2015 / 12 / 31$ & $2016 / 12 / 31$ & $2017 / 9 / 30$ \\
\hline F1 & 1.83151 & 1.08335 & 0.53206 & -0.38077 & -0.56375 & -0.6424 & -2.35179 \\
\hline F2 & 0.50978 & 0.92763 & 0.92061 & 2.07452 & 1.90048 & 1.24529 & -0.53581 \\
\hline F3 & -0.04829 & -0.76736 & -0.76501 & -1.17068 & 0.56882 & 0.77786 & -0.29908 \\
\hline F4 & -0.63125 & -0.74675 & -0.42723 & -0.23184 & 0.53441 & 0.17877 & -3.00047 \\
\hline 总得分 F & 0.55 & 0.28 & 0.17 & 0.15 & 0.51 & 0.3 & -1.43 \\
\hline
\end{tabular}

\section{3 影响分析}

从表 5 我们可以很直观地看到总得分走势整体是向下的。随着大股东股权质押率的不断增 长，乐视网的经营业绩整体是下降的，公司并没有因为股权质押获得融资而提高经营绩效， 反而是起到了负面影响。特别地, 我们也发现乐视网在2015年公司业绩有一个短暂的回升, 在下文中会重点分析。

再来看各主因子的变动趋势。长期偿债和盈利能力因子下降趋势非常明显, F1最高值出 现在 2011 年, 也就是说乐视网的上市以后负债水平在不断变高, 盈利能力在不断下降。外部 面临严峻的偿债风险, 内部却没有一个强大的造血能力, 经营业绩令人堪忧。营运能力和发 展能力因子走向大致相同, 在上市前期都有一个较为平稳的上升期, 但在近三年也都呈现出 急剧下降的趋势。短期偿债能力因子在 2015 年以前每年的变化较小, 但在 15 年这一个周期内 是呈现向上势头的, 这可能与贾跃亭在 2015 年那次规模最大的股权质押事件有关。贾跃亭用 其64.81\%的股权进行质押，获得大量现金流，并无息贷款给上市公司，使乐视网的短期偿债 能力在短时间内提升较多。各因子均在 2017 年经历谷底, 17年也确实是乐视财务危机全面爆 发的一年, 贾跃亭股权被冻结远走美国, 乐视高管变更, 资产重组, 负债累累, 经历了长时 间停牌。根据乐视网公告显示，2017年预亏116亿，贾跃亭的累计质押股权也在这一年达到历 史最高，超高的股权质押率对公司业绩起到了强烈的负面影响。

上文中，我们多次发现2015年的不同之处，而且贾跃亭在2015年还进行了一次规模最大 的股权质押行为, 那为何乐视在 15 年业绩会有所回升?

我们可以看到在2015年营运能力展现出较高水平, 发展能力也是所有年份里最好的。回 看表 2 营运能力的三个指标, 都与营业收入这一科目息息相关。翻阅年报发现, 乐视网 15 年营 业收入较上年增加了百分之九十以上, 增长非常迅猛, 也正是这一原因是的这一年营运能力 水平较高。乐视网2015年度的营业收入主要由广告业务、终端业务、会员及发行业务三部分 组成, 其中收入的 $46.78 \%$ 来源于终端业务, 根据年报显示, 终端业务当年的成本占据了总成 本的 $73.67 \%, 60.89$ 亿的收入对应的是 81.86 亿的成本, 大额的收入带来的却是 20.97 亿元的毛 亏损，虽然经营业绩的总得分较高，但实际情况却是盈利质量很差。

乐视网的终端业务主要为乐视致新的超级电视, 其走的是低价捆绑销售的模式, 买会员 赠电视, 用这样低于成本价的销售目的在于快速拓展、占领终端市场, 为乐视的视频业务提 供载体。乐视网大股东贾跃亭的高质押率无疑加大了现金流权和控制权的分离程度，增加了 代理成本, 为了实现他口中的生态化反, 让乐视超级电视选择这样一条低价销售之路, 定会 对公司的经营绩效带来负面影响。

再来看发展能力。上文提到的暴涨的营业收入无疑提高了公司的发展能力，另外我们还 需关注一下乐视的净利润增长率。乐视网 2015 年的净利润较上年增长了 $68.57 \%$, 但从表 6 我们 可以发现, 乐视的利润总额并不高, 但净利润却远高于利润总额, 公司的所得税费用连续三 年为负, 且数额很大。 
表6 利润与所得税费用

\begin{tabular}{c|c|c|c}
\hline 会计期间 & $2014-12-31$ & $2015-12-31$ & $2016-12-31$ \\
\hline 利润总额 & 72899104.84 & 74169222.09 & -328708520.9 \\
\hline 所得税费用 & -55897456.04 & -142947603.5 & -106815889.2 \\
\hline 净利润 & 128796560.9 & 217116825.6 & -221892631.7 \\
\hline
\end{tabular}

翻阅年报我们发现，大量的递延所得税资产使得所得税费用为负，而这些大量的递延所 得税资产其中 $83.63 \%$ 都是由可抵扣亏损造成的。表7给出了递延所得税资产的主要构成情况。

表7 递延所得税资产

\begin{tabular}{c|c|c|c}
\hline 项目 & 可抵扣暂时性差异 & 递延所得税资产 & 占比 \\
\hline 内部交易未实现利润 & $188,929,607.36$ & $47,232,401.84$ & $9.31 \%$ \\
\hline 可抵扣亏损 & $1,696,948,005.00$ & $424,237,001.25$ & $83.63 \%$ \\
\hline 坏账准备 & $204,414,434.86$ & $33,878,127.25$ & $6.68 \%$ \\
\hline
\end{tabular}

在上文已经提到的乐视致新大额亏损，这样的亏损乐视将其确认为可抵扣亏损，但亏损 的子公司是否可以在五年内转亏为盈属于会计职业判断, 我们无法准确预判, 这些可抵扣亏 损产生的递延所得税资产在合并报表里抵减所得税费用，使得合并净利润虚高，这无疑给了 乐视一个调节利润美化报表的机会。根据信号传递理论, 公司大股东频繁大量的股权质押行 为可能会对投资者传递出上市公司极度缺钱的信号, 在一定程度会影响投资选择, 另外由于 出质人和质权人之间信息不对称, 质权人会要求上市公司提供更多的财务信息, 对公司绩效 相对较为敏感, 这都使得公司会实施盈余管理调节报表, 提升公司经营业绩, 满足质权人的 要求。乐视利用大量的递延所得税资产来虚增净利润, 虽然让报表好看了许多, 但终究无法 产生现金流。由于股权质押而导致的这种盈余管理行为, 不仅欺瞒了投资者, 也麻痹了自己， 尽管表面公司的经营业绩变好，但长远来看影响是消极的。

\section{5. 结束语}

随着乐视网股权质押行为的不断增多，公司的经营绩效整体呈现下降趋势，尽管在2015 年乐视的业绩得分有了一个明显上升，但通过分析我们发现这是乐视调节利润进行盈余管理 的结果，总体来看，股权质押对于乐视的经营业绩的影响是负面的。股权质押是一把 “双刃 剑”，它以快捷成本低的融资优势吸引着上市公司各大股东的同时，还应关注它背后隐藏的 各项风险。因此，我们应规范大股东的股权质押行为，对其股权质押的额度进行一定限制， 同时还要进一步提升股权质押过程中的监督检查机能，维护质权方的利益，使股权质押这一 融资方式变得更加规范、安全。

\section{References}

[1] Lin Yan, Wei Lianbin, Li Wei. Research on Controlling Shareholders' Equity Pledge, Nature of Shares and Corporate Performance[J]. Business research,2018(02):50- 56.

[2] Zhao Ruixue. Study on Impact of Pledge of Ultimate Controller's Equity on Corporate Performance_-Based on the Empirical Data of Private Enterprise in GEM[J].Economic Research Guide, 2017(19):54-58.

[3] Chen Gongrong, Li Yiyi, Cai Shuren. Research on the Influence of Shareholder Pledge on Earnings Management[J]. Friends of Accounting, 2016(14):12-17.

[4] Li Hongtao. The Impact of Stock Pledge of Large Shareholders of Listed Companies on the Value of the Company: Take Huaying Technology as an Example[J]. Finance and Accounting, 2017(05):64-68. 